\title{
COMPETÊNCIA EM INFORMAÇÃO E NECESSIDADE DE PERTENCIMENTO DOS PAIS DE SURDOS
}

\author{
INFORMATION LITERACY AND NEED TO BELONG \\ FROM PARENTS OF THE DEAF
}

\author{
Ana Paula Pereiraa \\ Adriana Rosecler Alcaráb
}

\begin{abstract}
RESUMO
Introdução: Esta pesquisa aborda a contribuição da competência em informação para a necessidade de pertencimento dos pais de surdos. A necessidade de pertencimento envolve o sentimento de integração, conexão e aceitação do indivíduo pelo grupo. No caso da surdez, este vínculo se estabelece na relação entre os pais e a comunidade surda ou com outros pais, seja na igreja, na escola, na associação de pais, em eventos ou encontros para surdos. Destaca que a necessidade de pertencimento pode aproximar e instigar os pais a buscar, usar e compartilhar informação entre si, de modo que fortaleçam essas relações e desenvolvam as habilidades para competência em informação. Objetivo: Analisar a competência em informação dos pais de surdos e sua contribuição para a necessidade de pertencimento. Metodologia: Estudo exploratório e descritivo, de natureza qualiquantitativa a partir de uma pesquisa de campo. O locus foi constituído por duas instituições especializadas na área da surdez da região norte do Paraná. A população alvo foi composta por 34 pais de surdos, cujos filhos estudam nestas instituições e os dados foram coletados por meio de um questionário. Resultados: Dentre os resultados, identificou-se que a maioria dos pais se sente pertencido à comunidade surda, e este sentimento tende a favorecer o vínculo, 0 compartilhamento da informação e a participação na vida dos filhos surdos. Conclusões: Conclui-se que a necessidade de pertencimento dos pais de surdos contribui para a competência em informação ao ampliar habilidades e os laços afetivos.
\end{abstract}

Descritores: Competência em informação. Necessidade de Pertencimento. Surdez.

\section{INTRODUÇÃO}

Todo indivíduo tem a necessidade de estar vinculado e integrado a um grupo, sendo que este sentimento é saudável e benéfico. Essa necessidade é

\footnotetext{
a Mestre em Ciência da Informação pelo Programa de Pós-Graduação em Ciência da Informação da Universidade Estadual de Londrina (PPGCI-UEL). E-mail: appuel@yahoo.com.br

b Doutora em Psicologia pela Universidade São Francisco (USF). Professora do Programa de Pós-Graduação em Ciência da Informação (PPGCI-UEL). E-mail: adrianaalcara@gmail.com.
} 
concebida como necessidade de pertencer ou necessidade de pertencimento e está presente nos diversos relacionamentos: entre professores e estudantes, pais e filhos, pais e professores, pais e demais membros da família ou mesmo entre pais e outros pais. No contexto da surdez, por exemplo, quando os pais dialogam com outros pais de surdos, com a escola, professores (surdos ou ouvintes) tendem a se sentir fortalecidos e mais preparados para lidar com a surdez e auxiliar o filho surdo, ao mesmo tempo em que se aproximam da comunidade surda e isso reflete no seu aprendizado, na busca de informações e construção do conhecimento.

Quando os pais recebem o diagnóstico da surdez surgem conflitos, sentimentos e situações desafiadoras, muitas vezes provocadas pela falta de informação e dificuldade de lidar com o desconhecido. Mas estes desafios poderão ser amenizados e superados com apoio de outros pais que estão vivenciando a experiência da surdez. Neste caminho, com o apoio da comunidade de pais, da escola, da família, eles podem desenvolver as habilidades da competência em informação, que inclui aprender a sanar suas necessidades de informação, selecionar fontes de informação, usar, se apropriar e compartilhar informações e assim fortalecer o sentimento de pertencimento. $O$ que também pode motivar a si e a outros pais, de modo que a informação possa ser utilizada para enfrentar dificuldades e desafios e para promover o "aprender a aprender".

Como dito, ao desenvolverem estas ações, eles estão formando as habilidades para a competência em informação e quanto mais bem desenvolvidas estas habilidades melhores serão as oportunidades para a busca e a construção coletiva do conhecimento sobre a surdez. Para os pais de surdos, a formação e o desenvolvimento da competência em informação é imprescindível, já que os conduz à ações e posturas mais críticas, reflexivas e conscientes diante da informação. Ademais, a satisfação da necessidade de pertencimento favorece a competência em informação dos pais, pois quanto mais eles se sentem pertencentes e incluídos à comunidade surda ou à comunidade de pais, maiores serão as possibilidades de desenvolverem a competência em informação.

Entretanto, da mesma forma que na produção nacional, na literatura 
estrangeira percebemos que a temática da surdez ainda é pouco explorada na Ciência da Informação e, em especial, com seus familiares. Além disso, a questão motivacional, mais especificamente relativa à necessidade de pertencimento, também é pouco abordada em pesquisas da competência em informação (especialmente em âmbito nacional). Fazzioni, Vianna e Vitorino (2018, p. 204) indicam "[...] uma lacuna de estudos na temática da competência em informação, relacionada à questão emocional e afetiva".

Assim, este artigo traz um recorte dos resultados de uma pesquisa de dissertação, em que Pereira (2020) abordou a contribuição e relação da competência em informação com a necessidade de pertencimento dos pais de surdos. O estudo se justificou a partir da realidade de um grupo de pais muitas vezes em situação de vulnerabilidade, que permeados por dúvidas e incertezas precisam saber como e onde buscar informações sobre a surdez e satisfazer a necessidade de pertencimento. Deste modo, a contribuição para a Ciência da Informação implica em evidenciar que o desenvolvimento de habilidades da competência em informação, além de produzir conhecimento e aproximar o surdo da família, facilitando o convívio, propicia a motivação para aprendizagem ao longo da vida, o que será determinante nas escolhas e nas lutas que os pais enfrentam diariamente.

Nesse sentido, como fundamentação teórica, discutimos algumas concepções de surdez e a competência em informação e abordamos a motivação e a necessidade de pertencimento, na perspectiva da Teoria da Autodeterminação.

\section{A COMPETÊNCIA EM INFORMAÇÃO NO CONTEXTO DA SURDEZ}

O olhar que se tem hoje sobre a surdez é recente e fruto de muitas lutas e conquistas dos surdos. No século XV, por exemplo "[...] as pessoas que não podiam ouvir eram atiradas do alto dos rochedos, pois elas não eram consideradas humanas". (SILVA, 2010, p. 12). Posteriormente, a sociedade optou por oralizar os surdos, isto é, fazê-los falar por meio da "recuperação auditiva, tratamento de reabilitação e exercícios mecânicos". (SILVA, 2010, p. 12). Esta concepção clínico-terapêutica define a surdez como "[...] uma diminuição da capacidade de percepção normal dos sons, que traz ao indivíduo uma série de conseqüências ao seu desenvolvimento, principalmente no que diz 
respeito à linguagem oral". (BRASIL, 2006, p. 68). Em outras palavras, nesta concepção a surdez é entendida como uma doença a ser curada e que prejudica o desenvolvimento do surdo.

Segundo Skliar (2012, p. 07) este modelo amplificou e exagerou "[...] os mecanismos da pedagogia corretiva, instaurada nos princípios do século XX e vigente até os nossos dias. Foram mais de cem anos de práticas de tentativa de correção, normalização e de violência institucional [...]" que produziram o "[...] holocausto linguístico, cognitivo e cultural [...]" dos surdos. (SKLIAR, 2012, p. 16). Do lado oposto, a concepção pedagógica e social foi desenvolvida como "[...] um olhar antropológico e cultural" (SILVA, 2010), onde "A surdez é uma experiência visual que traz aos surdos a possibilidade de constituir sua subjetividade por meio de experiências cognitivolingüísticas diversas, mediadas por formas alternativas de comunicação simbólica, que encontram na Língua de Sinais, seu principal meio de concretização". (BRASIL, 2006, p. 71). A figura 1, representa os conceitos das concepções clínico-terapêutica e pedagógica e social em sentidos opostos.

Figura 1 - Concepção clínico-terapêutica X concepção pedagógica e social
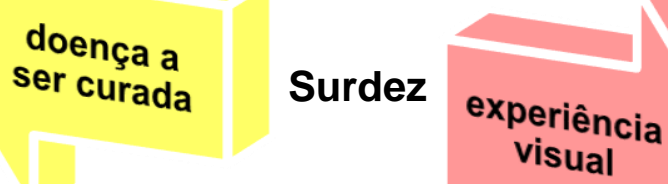

Fonte: Elaborado pelas autoras.

Vale salientar que a concepção pedagógica e social valoriza "[...] as potencialidades dos surdos, traduzidas por construções artísticas, lingüísticas e culturais, representativas dessa comunidade, que compartilha a possibilidade de conhecer e aprender, tanto mais por meio da experiência visual do que pela possível percepção acústica" (BRASIL, 2006, p. 70), sendo portanto significativa porque respeita o universo da surdez e a Língua de Sinais.

Apesar deste avanço que vai muito além de dois conceitos antagônicos, mas representa a história e as lutas dos surdos, a informação ainda aparece como um fenômeno conflitante, ora incompleta, ora complexa, principalmente 
para os pais. Nas palavras de Chiella (2007, p. 138) "A maior dificuldade que a maioria dos surdos enuncia em relação a família é a falta de informação, o que os leva muitas vezes a ter um sentimento de revolta". Nesse sentido, a Ciência da Informação precisa posicionar-se diante das dificuldades informacionais das populações vulneráveis (como os pais e filhos surdos), de modo responsável e ético e propor soluções e ações diante da informação. Isto é, propiciar meios e recursos que favoreçam o pensamento crítico e reflexivo dos indivíduos diante da informação, de tal modo que possam discernir, escolher e compreender a realidade, o contexto em que estejam inseridos.

No caso da surdez, por exemplo, tanto os pais, quanto bibliotecários, professores, profissionais da saúde, entre outros, necessitam de informações para que juntos possam encontrar respostas concernentes à vivência real dos surdos, tendo em vista que o modo como eles vão reagir e agir vai fazer toda diferença. Do mesmo modo, ao "ouvir a voz" dos grupos vulneráveis, como os pais dos surdos, a Ciência da Informação Ihes dá o direito de expressar suas dificuldades em relação à informação e dizer aquilo que querem e aquilo que realmente precisam. Nesse sentido, a competência em informação pode contribuir ao propiciar a resolução de problemas informacionais de modo criativo, utilizando-se do pensamento reflexivo e da criticidade.

Assim como a American Library Association (ALA) em 1989 já havia sinalizado, Dulzaides Iglesias e Molina Gómez (2007, p. 46, tradução nossa) também reforçam que "[...] um indivíduo competente em informação é aquele que aprendeu a aprender, que sabe como aprender; sabe como a informação é organizada, como encontrar e utilizar a informação de modo que outros possam aprender com ele". "São pessoas preparadas para a aprendizagem ao longo da vida, porque podem encontrar as informações necessárias para qualquer tarefa ou decisão". (ALA, 1989, p. 01).

Nesse sentido, a competência em informação requer um "[...] processo contínuo de interação e internalização de fundamentos conceituais, atitudinais e de habilidades específicas como referenciais à compreensão da informação e de sua abrangência [...]" (BELLUZZO, 2005, p. 38). Nessa linha de pensamento, Vitorino e Piantola (2009, p. 137, grifo nosso) afirmam que a competência em 
informação vincula-se à informação de modo complexo tendo em vista que "[...] envolveria aspectos objetivos, ligados às habilidades técnicas e à competência crítica, e aspectos subjetivos, os quais abrangem fatores como experiência pessoal, inspiração, criatividade e motivação [...]". Este último aspecto é importante visto que impulsiona as ações dos indivíduos, levando-os a não desistir, mas sim persistir e encontrar prazer na realização de suas metas.

Essas diferentes habilidades para a compreensão, reflexão e crítica em relação à busca, uso e compartilhamento da informação da mesma forma estão presentes na proposta conceitual para a competência em informação mais recente da Association of College \& Research Libraries (ACRL), que a considera como

[...] conjunto de habilidades integradas que abrange a descoberta reflexiva de informação, a compreensão de como a informação é produzida e valorizada, o uso de informação na criação de novos conhecimentos e a participação ética nas comunidades de aprendizagem. (ACRL, 2016, p. 03, tradução nossa).

Desse modo, entendemos que a competência em informação pode auxiliar os pais de surdos nas suas necessidades informacionais, nas ações de busca e uso da informação e até mesmo no compartilhamento da informação com outros pais. O que pode torná-los multiplicadores do conhecimento, além do aprender a aprender, não somente em relação à saúde, mas também em aspectos como educação, comunicação, direitos, trabalho, lazer, entre outros.

Com isso concordamos com Amadeo e Vitorino (2013, p. 14) quando ressaltam que a competência em informação é "[...] um novo paradigma a ser alcançado pelas pessoas que buscam a cidadania, emancipação, qualidade de vida, saúde, lazer [...]". Isso implicaria em mudanças no modo de ser e de fazer em relação à informação, sendo que os pais de surdos tendem a ser favorecidos neste caminho. Nessa direção, acreditamos que esta pesquisa alinha-se às orientações do Manifesto de Florianópolis sobre a competência em informação quando recomenda aos profissionais da Ciência da Informação "Atuar junto às comunidades (populações vulneráveis e minorias) para produzir conteúdos informacionais sobre sua história, cultura e meio social". (MANIFESTO..., 2013).

Para os surdos, entender que são membros de uma comunidade com cultura e Língua própria - a comunidade e a cultura surdas e a Língua de Sinais, 
situa-os no mundo e lhes dão o sentimento de pertencimento. De acordo com Chiella (2007, p. 81) "É no encontro na comunidade que os surdos atribuem significado à experiência vivida e ao conhecimento de mundo". Assim, reconhecemos que a necessidade de pertencer ou de estabelecer vínculos influencia a motivação para aprendizagem e pode favorecer o desenvolvimento da competência em informação.

\subsection{NeCESsidade de Pertencer e a CompetênCIA Em Informação}

A motivação leva os indivíduos a alcançarem o que querem, sem desistir facilmente, mas persistindo para atingir seus propósitos. Para uma pessoa motivada os desafios não são dificuldades ou obstáculos, mas tornam-se fatores que instigam e de certo modo inquietam. Desse modo, julgamos que pais de surdos motivados estão mais propensos a sanar suas necessidades informacionais e de pertencimento, ainda que a situação seja complexa. Eles tendem a desenvolver as habilidades cognitivas, técnicas e atitudinais, que constituem a competência em informação, conforme podemos notar na figura 2.

\section{Figura 2 - Habilidades para competência em informação aplicada aos pais de surdos}

\begin{tabular}{|c|c|}
\hline & $\begin{array}{l}\text { - Os pais precisam das habilidades técnicas para lidar com a informação, ou } \\
\text { seja, precisam conhecer os recursos informacionais para a busca e o } \\
\text { compartilhamento da informação; perceber suas dificuldades em relação a } \\
\text { esses recursos. }\end{array}$ \\
\hline & $\begin{array}{l}\text { - Os pais desenvolvem as habilidades cognitivas ao transformarem a informação } \\
\text { sobre a surdez em conhecimento, atribuindo-Ihe sentido, se apropriando, } \\
\text { modificando concepções e preconceitos em relação ao surdo e aprendendo a } \\
\text { aprender. }\end{array}$ \\
\hline $\mathrm{H}$ & $\begin{array}{l}\text { - Os pais desenvolvem as habilidades atitudinais quando buscam informação } \\
\text { sobre a surdez que gere uma mudança de atitude, ao descobrir e sanar suas } \\
\text { necessidades informacionais e de pertencimento. Elas também impactam na } \\
\text { disposição dos pais em desenvolver os outros dois conjuntos de habilidades. E } \\
\text { isso pode influenciar nas suas ações em relação aos filhos. }\end{array}$ \\
\hline
\end{tabular}

Fonte: Elaborado pelas autoras.

De forma geral, para desenvolver as habilidades técnicas e cognitivas a pessoa dependerá das habilidades atitudinais (crenças, valores, atitudes) que são internas e individuais e estão diretamente relacionadas ao "querer fazer". 
Assim como, as habilidades atitudinais são instigadas pelas técnicas e cognitivas. Dulzaides Iglesias e Molina Gómez (2007) se referem ao "querer fazer" como um conjunto de aspectos motivacionais, que influencia na decisão da pessoa em realizar ou não determinada ação e que pode ser impactado por fatores internos e externos à pessoa.

Nesse sentido, é que visualizamos a relevância de se estudar a motivação. Quanto a isso, é necessário enfatizar que existem diferentes teorias que subsidiam os estudos da motivação. Neste artigo utilizamos uma das necessidades psicológicas da Teoria das Necessidades Básicas, que integra a Teoria da Autodeterminação (TAD) de Deci e Ryan e que foi proposta na década de 1970. De forma geral, a TAD dá subsídios para a compreensão dos diferentes tipos de motivação e para tal possibilita investigar como as tendências naturais para o crescimento e as necessidades psicológicas interagem com as condições socioculturais. Assim como os fatores sociocontextuais que apoiam ou impedem as pessoas em prosperar a partir da satisfação de suas necessidades psicológicas básicas. (DECl; RYAN, 2000; REEVE; DECl; RYAN, 2004; RYAN; DECI, 2017).

Nos referindo especificamente à Teoria das Necessidades Básicas, essa consiste na necessidade de pertencer, necessidade de competência e necessidade de autonomia. Tais necessidades "[...] movem os seres humanos, sendo definidas como os nutrientes necessários para um relacionamento efetivo e saudável destes com seu ambiente". (GUIMARÃES; BORUCHOVITCH, 2004, p. 145). De acordo com Ryan e Deci (2017), cada pessoa tem internamente uma tendência natural ao crescimento e desenvolvimento. No entanto, segundo os autores, embora natural, essa tendência também é condicional e requer apoio social e ambiental para que as pessoas satisfaçam as suas necessidades psicológicas básicas.

Neste estudo o foco centrou-se na necessidade de pertencer ou de pertencimento, que segundo Reeve, Deci e Ryan (2004) é a necessidade de estabelecer vínculos estreitos e seguros com os outros, visando o envolvimento emocional e interpessoal. Quando essa necessidade é satisfeita as pessoas sentem-se motivadas para o relacionamento autêntico com as outras pessoas, 
aproximando-se daquelas que demonstram atenção e respeito em relação a elas. Refletindo sobre o contexto desta pesquisa, acreditamos que uma das formas de garantir a autenticidade das relações e a aceitação seria 0 conhecimento da cultura surda e do aprendizado da Língua de Sinais por parte dos pais dos surdos.

Baumeister e Leary (1995) ressaltam que a experiência de pertencer relaciona-se a importantes processos psicológicos, dentre os quais podemos citar, o aumento dos recursos internos da pessoa para enfrentar desafios, situações de fracassos ou conflitos; o fortalecimento do senso de identidade pessoal e a disposição para internalizar valores sociais relevantes. Eles ainda reforçam que grande parte das ações humanas estão inclinadas para a satisfação da necessidade de pertencer, dessa forma, as pessoas buscam estabelecer vínculos sociais de maneira espontânea e sem exigir condições especiais.

Nessa perspectiva, inferimos que satisfazer a necessidade de pertencer é essencial para os pais e para os filhos surdos (que precisam se sentirem incluídos e realizados). Isso porque ela "[...] reflete a tendência de estar integrado, conectado e aceito pelos outros". (ALCARÁ, 2007, p. 27). No caso do surdo, estes "outros" podem ser tanto os pais, tios, primos, avós, quanto os amigos, professores (a escola em geral) em que as relações, os laços e os vínculos tendem a ser tornar mais intensos e no caso dos pais pode ser a família, a comunidade escolar, a comunidade de pais, a comunidade surda, entre outros.

Vale destacar que "Os vínculos exercem um papel importante na vida das pessoas, pois quando percebem que fazem parte de um grupo, as pessoas sentem-se valorizadas e respeitadas". (AKAICHI, 2014. p. 67). Pais e filhos surdos precisam sentir-se reconhecidos e ao mesmo tempo atribuir valor à comunidade surda ou à comunidade de pais, por exemplo. Isso porque a necessidade de pertencimento "[...] se refere não só à necessidade de estar inserido em um grupo, mas à qualidade dos laços estabelecidos com outros indivíduos e o sentimento de aceitação presente". (GASTAL; PILATI, 2016, p. 286).

Em síntese, a necessidade de pertencimento está relacionada à 
percepção da pessoa em pertencer, fazer parte de uma situação, de um grupo ou de um ambiente, tendo em vista o estabelecimento de vínculos saudáveis e a percepção de aceitação. Isso torna a pessoa mais motivada e comprometida com suas próprias ações. A figura 3 , a seguir, apresenta a relação entre a necessidade de pertencimento, a motivação e a competência em informação, evidenciando a influência de uma sobre a outra.

Figura 3 - Ciclo da relação entre a necessidade de pertencimento, motivação e Competência em informação



Fonte: Elaborado pelas autoras.

Acreditamos que a competência em informação pode contribuir para a inclusão e a necessidade de pertencer dos pais e dos filhos surdos, pois quando os pais vão sanando suas necessidades informacionais e conhecendo outros surdos e outros pais, eles também vão aprendendo a lidar com a surdez, ao mesmo tempo em que apoiam os filhos e fortalecem o sentimento de pertencimento. Igualmente, ao sentirem-se pertencidos e com vínculos estabelecidos a competência em informação tende a ser potencializada.

\section{PROCEDIMENTOS METODOLÓGICOS}

Esta pesquisa buscou analisar a competência em informação dos pais de surdos e sua contribuição para a necessidade de pertencimento. Considerando que as pesquisas com esse tipo de público ainda são pouco exploradas na Ciência da Informação, foi desenvolvida uma pesquisa de campo, exploratória e 
descritiva, com abordagem mista - qualiquantitativa, tendo como instrumento de coleta de dados um questionário, com questões fechadas e abertas.

O universo foi composto pelos pais de surdos, sendo que selecionamos uma amostra de pais que tem seus filhos atendidos por duas instituições especializadas na área de surdez do norte do Paraná. Essa escolha se justificou pelo fato de que esses pais possuem um maior conhecimento e convívio com surdos, uma vez que seus filhos estudam nos institutos que atendem crianças, adolescentes e adultos com esse tipo de necessidade.

A instituição 1 se caracteriza como um centro especializado na área surdez, que tem 0 intuito de propiciar o desenvolvimento cognitivo, a aprendizagem da Libras e apoio à escolarização dos surdos. A instituição 2 dedica-se ao ensino especial, com atuação nas áreas de educação (Educação Infantil, Ensino Fundamental e Ensino Médio) e Saúde (Serviço Social, Psicologia, Medicina: Otorrinolaringologista e Neurologista, Fonoaudiologia, Odontologia e Terapia Ocupacional).

Após os procedimentos quanto à autorização das instituições para a coleta de dados e aprovação pelo Comitê de Ética em Pesquisa, foi realizado um pré-teste do instrumento com alguns pais que não participaram da amostra final da pesquisa. Em seguida, com o apoio da direção das duas instituições, enviamos o instrumento final para uma amostra de 58 pais, sendo que destes, 34 responderam ao questionário (19 da instituição 1 e 15 da instituição 2).

$\mathrm{O}$ instrumento contemplou questões relativas às experiências dos pais, dentre as quais suas necessidades informacionais, as fontes de informação que utilizaram no decorrer da vida de seus filhos, habilidades informacionais que possuem e dificuldades que encontram nesse processo e a necessidade de pertencimento, todas permeadas pela competência em informação. Porém, conforme já mencionado na introdução deste artigo, os resultados aqui apresentados serão concentrados na relação da competência em informação com a necessidade de pertencimento dos pais de surdos.

Quanto à estratégia de análise, optamos por fazer uma descrição e análise conjunta dos dados quantitativos e qualitativos, provenientes das 
questões fechadas e abertas que foram organizados, tabulados, representados em tabelas e analisados a partir da literatura científica.

\section{ANÁLISE E DISCUSSÃO DOS RESULTADOS}

A seguir apresentamos a análise e a discussão dos resultados, com ênfase no modo como a competência em informação contribui para a necessidade de pertencimento dos pais de surdos.

\subsection{Contribuição da CompetênCia em InformaçÃo para a NeCESSidAde de Pertencimento dos Pais de Surdos}

Para atender a proposta desta categoria de análise utilizamos questões do instrumento que versavam sobre o sentimento de pertencimento dos pais em relação à comunidade surda, à participação nas associações de pais e amigos dos surdos, à frequência dos pais em eventos, encontros ou festas para surdos. Assim como, se as informações que os pais sabem ajudam no sentimento de pertencimento em relação à comunidade de pais de surdos e se o fato de se sentirem pertencentes à comunidade de pais os ajudam a aprender a lidar com a surdez.

Nestas questões os participantes deveriam assinalar uma opção entre as dispostas no questionário. Em relação ao sentimento de pertencimento à comunidade surda, os participantes da instituição 1 ficaram distribuídos da seguinte forma: $63,15 \%(n=12)$ se sentem pertencidos (pertencentes); $26,31 \%$ $(n=5)$ se sentem pouco pertencidos; 5,26\% $(n=1)$ declarou sentir-se sem pertencimento e 5,26\% ( $n=1)$ não soube ou não respondeu. Destacamos o fato de 12 pais selecionarem a opção pertencido, demonstrando que identificam um vínculo à comunidade surda, que surge "[...] na contemporaneidade com o sentimento de pertencimento a um grupo em que prevalecem as sensações de bem-estar e de segurança". (CHIELLA, 2007, p. 80).

No que se refere aos participantes da instituição $2,66,66 \% \quad(n=10)$ declararam se sentir pertencidos; $13,33 \%(n=2)$ se sentem pouco pertencidos; $13,33 \%$ sem pertencimento e $6,66 \%$ não soube ou não respondeu. Tanto na 
instituição 1 quanto na instituição 2 os dados revelaram que a maioria dos participantes se sentem pertencidos à comunidade surda, o que indica o primeiro caminho para a aproximação, vínculo, informação e participação tanto na vida dos filhos surdos, quanto no diálogo com outros pais e outros surdos, que pode levá-los a conhecer e aprender além de suas próprias experiências.

Estar próximo e conhecer a comunidade surda é um dos primeiros passos para aprender mais sobre a surdez e fortalecer esse sentimento que pode impulsionar a busca pela informação e o aprendizado. Segundo Silva (2010, p. 139) "Os benefícios advindos da participação do ouvinte nessa comunidade são vários, como a oportunidade de conhecer o sujeito surdo de perto, aprender a Língua de Sinais e conhecer os costumes e hábitos vivenciados pelo surdo, tanto individualmente quanto em comunidade".

Associando a concepção da competência em informação ao contexto aqui estudado, os pais precisam aprender a aprender continuamente, para aprender a lidar com a surdez nas diferentes fases da vida dos filhos. Vale pontuar que "[...] pessoas competentes em informação são aquelas que aprenderam a aprender. Elas sabem como aprender porque sabem como o conhecimento é organizado, como encontrar informações e como usar as informações de forma que outras pessoas possam aprender com elas" (ALA, 1989, tradução nossa), como por exemplo, o aprendizado obtido com o compartilhamento de informação na comunidade de pais. O aprender a aprender engloba a autonomia e a independência em relação ao aprendizado, que também está entre as habilidades requeridas para a competência em informação.

Um aspecto importante além da comunidade surda é o familiar sentir-se pertencido à comunidade de pais porque este vínculo pode levá-lo a compartilhar suas experiências, vivências e conhecimentos com os outros pais. Por isso, questionamos se os participantes já foram ou se são membros de associações de pais e amigos dos surdos, sendo que na instituição 1, 52,63\% $(n=10)$ declaram que sim; 42,10\% ( $n=8)$ disseram não e 5,26\% ( $n=1)$ não soube ou não respondeu. Esses dois primeiros dados chamam a atenção: o número de pais que participam de instituições e em contrapartida o número significativo de pais que não são membros, dada a relevância das associações como fonte 
de informação e conhecimento sobre a surdez, além das ações por elas realizadas.

$\mathrm{Na}$ instituição 2, 66,66\% ( $n=10)$ declararam que não foram ou não são membros de associações de pais e amigos dos surdos; $26,66 \%(n=4)$ disseram que sim, já foram membros e $6,66 \%(n=1)$ não soube ou não respondeu. É um dado expressivo, especialmente em relação aos pais que não são membros de associações, já que conforme mencionado, tais associações têm papel relevante, tanto para os pais quanto para os filhos surdos. Entendemos que é imprescindível que os pais se integrem às associações, uma vez que isso pode contribuir para a construção coletiva da cidadania e atuação social e política concernente ao princípio da competência em informação, isto é, o "[...] o uso inteligente, crítico, reflexivo, criativo, responsável, ético e efetivo da informação para a transformação do conhecimento, resolução de problemas e exercício da cidadania em um aprender contínuo ao longo da vida". (SANTOS, 2016, n.p.).

Em outro momento, para verificar se os participantes se envolvem nas atividades dos surdos, indagamos quanto à frequência em eventos, encontros e festas para surdos, tendo em vista que isto também influencia o sentimento de pertencimento. Segundo Dizeu e Caporali (2005, p. 594)

\begin{abstract}
A comunidade surda pode ser representada por associações, igrejas, escolas, clubes, ou seja, qualquer lugar onde um grupo de surdos se reúne e divulga sua cultura, troca idéias e experiências e usa a Língua de Sinais. Dessa forma ela exerce um papel construtor para a identidade surda, pois é por meio dela que ocorrem as identificações com seus pares e a aceitação da diferença, não como um deficiente ou não-normal, mas com uma cultura rica que possui valores e Língua própria.
\end{abstract}

Além disso, "[...] não existe somente uma comunidade surda, mas, sim, diversas comunidades, como a da igreja, da escola, do hip hop, dos líderes e tantas outras que evidenciam sua identidade cultural". (SILVA, 2010, p. 139). $\mathrm{Na}$ tabela 1 a seguir apresentamos os resultados obtidos nas instituições 1 e 2 em relação à frequência em eventos. Vale salientar que em algumas alternativas não obtivemos respostas, por isso quando contabilizado, o percentual total não atinge $100 \%$. 
Tabela 1- Frequência dos pais em eventos, encontros ou festas para surdos

\begin{tabular}{|c|c|c|c|c|c|c|c|c|c|c|c|c|c|c|c|c|}
\hline \multirow{3}{*}{ Eventos } & \multicolumn{8}{|c|}{ INSTITUIÇÃO 1} & \multicolumn{8}{|c|}{ INSTITUIÇÃO 2} \\
\hline & \multicolumn{2}{|c|}{$\begin{array}{c}\text { Com } \\
\text { frequência }\end{array}$} & \multicolumn{2}{|c|}{ Às vezes } & \multicolumn{2}{|c|}{$\begin{array}{l}\text { Rara- } \\
\text { Mente }\end{array}$} & \multicolumn{2}{|c|}{ Não vão } & \multicolumn{2}{|c|}{$\begin{array}{c}\text { Com } \\
\text { frequência }\end{array}$} & \multicolumn{2}{|c|}{ Às vezes } & \multicolumn{2}{|c|}{$\begin{array}{l}\text { Rara- } \\
\text { mente }\end{array}$} & \multicolumn{2}{|c|}{ Não vão } \\
\hline & $\mathrm{N}$ & $\%$ & $\mathrm{~N}$ & $\%$ & $\mathrm{~N}$ & $\%$ & $\mathrm{~N}$ & $\%$ & $\mathrm{~N}$ & $\%$ & $\mathrm{~N}$ & $\%$ & $\mathrm{~N}$ & $\%$ & $\mathrm{~N}$ & $\%$ \\
\hline Escola & 9 & 47,36 & 6 & 31,57 & 3 & 15,78 & 1 & 5,26 & 7 & 46,66 & 6 & 40 & - & - & 1 & 6,66 \\
\hline $\begin{array}{l}\text { Associa } \\
\text { ção de } \\
\text { pais }\end{array}$ & 7 & 36,84 & 5 & 26,31 & 3 & 15,78 & 3 & 15,78 & 1 & 6,66 & 2 & 13,33 & 3 & 20 & 4 & 26,66 \\
\hline Igreja & 8 & 42,10 & 2 & 10,52 & 3 & 15,78 & 4 & 21,05 & 4 & 26,66 & 2 & 13,33 & 3 & 20 & 3 & 20 \\
\hline
\end{tabular}

Fonte: Dados da pesquisa.

Os resultados da tabela 1 mostram que poucos pais, de ambas as instituições, participam com frequência de eventos relacionados aos surdos na escola, na associação de pais e na igreja, o que pode impossibilitar o compartilhamento de informação entre os pais. O ideal seria que todos os pais se envolvessem, frequentassem e participassem de modo contínuo das atividades para seus filhos, pois é no grupo que as relações se fortalecem, assim como a informação e o sentimento de pertencimento. Quadros (1997, p. 108) ressalta que "[...] a escola deve ir além da relação profissional, e, consequentemente, abranger a relação pais e filhos. Os pais normalmente, não sabem ser pais de crianças surdas".

Dada a relevância da escola, salientamos que

Os profissionais que assumem a função de passar as informações necessárias aos pais devem estar preparados para explicar que existe uma comunicação visual (a Língua de Sinais) que é adequada à criança surda, que essa Língua permite à criança ter um desenvolvimento da linguagem análogo ao de crianças que ouvem, que essa criança pode ver, sentir, tocar e descobrir o mundo a sua volta sem problemas, que existem comunidades de surdos; enfim, devem estar preparados para explicar aos pais que eles não estão diante de uma tragédia, mas diante de uma outra forma de comunicar que envolve uma cultura língua visual-espacial. Deve-se garantir à família a oportunidade de aprender sobre a comunidade surda e a Língua de Sinais. (QUADROS, 1997, p. 29).

Profissionais preparados fazem toda diferença na vida das famílias. Além disso, a autora cita programas que poderiam ser desenvolvidos pela escola para estreitar as relações entre pais e filhos:

a) atividades para os pais orientadas por adultos surdos e profissionais especializados para discussão sobre aspectos sociais, lingüísticos e culturais da comunidade surda; b) 
programas para os pais e seus filhos que envolvam a interação usando a LIBRAS orientados por adultos surdos (jogos, brincadeiras, artes, passeios); c) visitas sistemáticas às residências dos alunos feitas por pessoas surdas. (QUADROS, 1997, p. 109).

Em relação aos resultados da instituição 2 é também importante enfatizar que é uma escola que possui "[...] toda uma estrutura formalizada, com professores, currículo, seriação, projeto político-pedagógico e atendimento específico [...]" (SILVA, 2010, p. 146) para os surdos. Neste caso, por se tratar de uma instituição de escolarização parece que implicaria em uma participação maior se comparada à instituição 1 , que recebe os surdos apenas no contraturno. Sendo que os surdos da instituição 1 recebem sua formação em escolas de ouvintes, cuja maioria dos estudantes são ouvintes.

Desta amostra da instituição 2, apenas um participante vai com frequência aos eventos da associação de pais. A inassiduidade dos demais pode enfraquecer 0 grupo e dificultar o compartilhamento de informações e experiências. Vale lembrar que, de acordo com Chiella (2007, p.145), "A associação e a comunidade de surdos são espaços exaltados pelos surdos como aqueles onde é possível viver a surdez e significá-la a partir do olhar do outro surdo $[\ldots] "$.

Guarinello e Lacerda (2007, p. 109) ressaltam que o grupo de pais/familiares de surdos é o espaço ideal para "[...] poder ouvir e falar sobre seus filhos e problemas, trocar experiências, dúvidas, inquietações, auxiliando na aceitação da surdez e apontando caminhos para o desenvolvimento pleno dos sujeitos surdos e de suas famílias". Nesse sentido, quando não há diálogo entre os pais, o sentimento de pertencimento à comunidade de pais se enfraquece, dificultando o compartilhamento de experiências, informações, desafios. Isto é, a baixa frequência nos eventos da escola e da associação de pais representa um impacto nas oportunidades de compartilhar e isso pode refletir na competência em informação.

Vale destacar que a frequência na igreja foi um dos itens do questionário porque esta instituição religiosa também é um espaço de apropriação e construção de identidade que, tanto os surdos quanto a família, podem participar e se sentir pertencentes. Em relação à frequência a igreja, aproximadamente 
$42 \%$ da instituição 1 e $26 \%$ da instituição 2 participam com mais frequência. Nesse item do instrumento o participante também tinha a opção de acrescentar informações e em relação à igreja uma das participantes destacou que: "A igreja que frequentamos é para ouvintes, interpreto o culto para minha filha"; uma outra também informou que participa de "Encontro de grupos de igrejas onde se reúnem os surdos".

Destacamos ainda alguns comentários quanto à importância da fé e religiosidade, em que uma das participantes declarou que a experiência com a surdez é: "Uma experiência muito boa pois meu filho é um presente de Deus em minha vida". Nesta linha de pensamento outra participante salientou a relevância da fé: "[...] com muita, muita fé em Deus, mas graças a Deus é uma pessoa inteligente [...] especial [...] a experiência que tive com ela é que Deus é o médico dos médicos e que fé em Deus é tudo". Acreditamos que estes sentimentos fortalecem os pais, tornando-os confiantes, seguros e capazes de lidar com a surdez, de modo que a necessidade de pertencimento na família é favorecida.

Em casa colocamos Deus a frente de todas as decisões. Dessa forma conseguimos demonstrar amor, respeito uns aos outros. Mesmo que tenhamos problemas, um bom diálogo resolve. (Meu filho) é minha joia rara que Deus me deu, é um filho carinhoso, esforçado e muito feliz. Amo por toda eternidade. (Relato de uma das participantes).

Além disso, alguns participantes mencionaram outros eventos que frequentam, como por exemplo, Eventos sociais e políticos e Palestras, que também atendem os princípios das dimensões política e ética da competência em informação, com a participação ativa e o engajamento social. Tais ações estão alinhadas com elementos da dimensão política da competência em informação, que no entender de Lucca e Vitorino (2018, p. 4122) "[...] incluem a cidadania, [...] a busca pela justiça social e pela redução de desigualdades, [...] as habilidades sociopolíticas, a responsabilidade social e o pensamento crítico".

Para verificar o sentimento de pertencimento à comunidade de pais, questionamos os participantes em relação às informações que eles sabem e se essas os ajudam a se sentirem pertencidos à comunidade de pais de surdos. Entre os pais da instituição 1, 47,36\% ( $n=9)$ disseram que sempre; $21,05 \%(n=4)$ afirmaram que quase sempre; $21,05 \%(n=4)$ às vezes; $5,26 \%(n=1)$ nunca $e$ 
$5,26 \%$ ( $n=1$ ) não soube ou não respondeu. Na instituição 2, os resultados obtidos foram: $13,33 \%(n=2)$ declaram que sempre; $46,66 \%(n=7)$ quase sempre; $26,66 \%(n=4)$ optaram por às vezes; $13,33 \%(n=2)$ não souberam ou não responderam. Vale destacar que apenas dois participantes acham que sempre as informações que sabem ajudam no sentimento de pertencimento à comunidade de pais, revelando uma dificuldade que eles podem ter em perceber a informação como elo com os outros pais, elemento com potencial de aproximálos ao invés de distanciá-los.

Ainda averiguamos se o fato de se sentirem pertencidos à comunidade de pais os ajudam a aprender a lidar com a surdez. No caso dos pais da instituição 1 as respostas foram: $52,63 \%(n=10)$ disseram que sempre; $15,78 \%(n=3)$ declaram que quase sempre, $26,31 \%(n=5)$ às vezes e $5,26 \%(n=1)$ nunca. Os dados indicaram que quase $53 \%$ dos participantes dessa instituição relacionam o pertencimento com a aprendizagem e que para eles o próprio grupo de pais é concebido como fonte de informação sobre a surdez. Quanto à instituição 2, 60\% $(n=9)$ assinalaram sempre; $13,33 \%(n=2)$ quase sempre; $13,33 \%(n=2)$ optaram por às vezes, $6,66 \%(n=1)$ declarou nunca e $6,66 \%(n=1)$ não soube ou não respondeu. Igualmente a instituição 1, 60\% dos participantes da instituição 2 acreditam que se sentirem pertencidos à comunidade de pais ajuda a aprender a lidar com a surdez.

É importante destacar que a necessidade de pertencer e o aprender integram a competência em informação, aqui entendida como a "[...] habilidade de definir, localizar, acessar, avaliar e usar a informação de forma ética e socialmente responsável como parte de uma estratégia de aprendizado ao longo da vida". (VITORINO; PIANTOLA, 2009, p. 135). No cenário da surdez, os pais ao lidarem com a informação precisam sentir-se pertencentes, motivados, impulsionados e com desejo de aprender e de se apropriar, descobrindo prazer em conhecer, ao mesmo tempo em que superaram desafios.

\subsection{Vivências dos Pais, Necessidade de Pertencimento e a Competência em INFORMAÇÃO}

Não se pode deixar de mencionar outros aspectos motivacionais 
decorrentes das vivências diárias dos pais que podem permear tanto a necessidade de pertencimento quanto a competência em informação. No discurso de uma das participantes da instituição 1, ficou evidente o envolvimento e o comprometimento da família com o apoio da instituição escolar: "Me sinto uma vencedora, com muito esforço da família meu filho conseguiu fazer faculdade, pós [graduação], é professor e já foi [político]. Mas Ihe digo uma coisa, se a família não pegar firme junto com a escola o progresso é muito pouco".

Esse envolvimento da família para enfrentar conjuntamente os diferentes desafios em relação aos filhos surdos contribui para o fortalecimento e pertencimento dos pais. Inclusive aqui vale retomar Baumeister e Leary (1995), quando enfatizaram que a percepção de vínculo e pertencimento aumenta os recursos internos da pessoa para superar os desafios. O que também pode ser confirmado tal como declarou uma das participantes da instituição 1 , no trecho a seguir:

As experiências tanto ruim, como fácil ou aceitável que encontramos no decorrer da vida de meu filho nos fizeram nos sentir mais fortes. Nós como família a todo momento fomos testados na nossa confiança mas essa nunca perdemos, o medo do mundo que o cercava sempre tivemos até hoje, nunca deixei que ele me dominasse [...]

Souza (2011, p. 93) explica que "Nós, homens e mulheres somos os únicos seres capazes de aprender com alegria e prazer, na convicção de que é possível uma transformação nossa e da sociedade". Corroborando com essa ideia, uma das participantes da instituição 2 ressaltou: "Minha filha me ensinou que as dificuldades nos fazem crescer em sabedoria, experiência e sentimento. Me tornei uma pessoa melhor e sou grata por ela em minha vida".

Percebemos que os filhos surdos auxiliam e fortalecem os pais propiciando experiências de aprendizagem e crescimento pessoal como destacou outra participante da instituição 1: "[...] nunca medi esforços sempre correndo com ela não fazendo questão dos preconceitos [...]". De fato, em muitas situações é preciso saber lidar com situações excludentes, e isso também é um modo de aprendizado para os pais, ao aprenderem lidar com o preconceito e a indiferença, como lembrou a participante da instituição 1: "Tive sim muito, muito 
preconceito, muitas dificuldades. Muita dor, preocupação [...]".

Souza (2011, p. 93) ressalta que "Aprender é uma descoberta criadora, curiosa, com abertura ao risco e à aventura do ser, pois ensinando se aprende e aprendendo se ensina". Mas para isso, é necessário que os laços familiares sejam fortalecidos com outros sentimentos que aproximem a família, como explicou uma participante da instituição 2: "[...] nós passamos um grande afeto amoroso". Nesse sentido, destacamos a experiência de outra participante da instituição 1: "É um filho do coração que alguém o rejeitou e eu acolhi com todo meu amor. Desde a primeira semana de vida eu o acolhi em meus braços e nunca mais o deixei". Já a participante da instituição 1 enfatizou que os "[...] filhos são amorosos, compreensivos, inteligentes. Tenho paciência com eles pois eles são gêmeos, eles são tudo pra mim. [...] Amo meus filhos".

Tais resultados permitem inferir que a competência em informação está vinculada à necessidade de pertencimento, sendo que uma contribui para outra. Isso pode ser percebido quando os pais identificam nos amigos e colegas a oportunidade de compartilhar experiências e informações ao lidarem com seus desafios e recebendo apoio. Por outro lado, a necessidade de pertencer pode ser prejudicada quando eles encontram dificuldade de dialogar sobre a surdez com amigos, colegas, outros pais, professores etc.

Essas oportunidades de compartilhamento, troca de experiências e apoio que os pais percebem em relação aos amigos e colegas reforça o que Reeve, Deci e Ryan (2004) alertaram quanto à importância dos vínculos e relacionamento com outras pessoas. De acordo com esses autores, a satisfação da necessidade de pertencer leva a relacionamento autêntico e seguro com os outros, assim como promove a atenção e o respeito.

Em ambas instituições os dados indicaram que a maioria dos pais se sente pertencente à comunidade surda e esse sentimento é primordial, pois pode fazer com que eles se aproximem e participem ativamente da vida dos filhos surdos, ao dialogarem com outros pais e outros surdos. Vale salientar que quando os pais desenvolvem habilidades para lidar com a informação e conhecem outros surdos, sentem-se mais motivados, preparados e seguros para lidar com a surdez. Um exemplo disso, está no fato de utilizarem as próprias 
instituições como fonte de informação. Outro aspecto que merece destaque é o papel da fé na vida dos pais, que além de fortalecê-los, torna-os confiantes e capazes de lidar com a surdez, de modo positivo, como uma experiência benéfica e de aprendizado, que impulsiona a satisfação em relação à necessidade de pertencimento e a competência em informação nas famílias.

\section{CONSIDERAÇÕES FINAIS}

A maioria dos pais de surdos desta pesquisa se diz pertencido à comunidade surda, resultado que demonstrou a identificação de um vínculo e afetividade. Por meio desse sentimento eles podem apoiar-se, criar laços, compartilhar informação e participar da vida dos filhos surdos, o que pode leválos ao conhecimento e aprendizagem com a experiência do outro (surdos, pais, amigos), além de suas experiências pessoais.

Salientamos que as associações de pais são importantes fontes de informação e de conhecimento sobre a surdez. Apesar disso, em uma das instituições estudadas, a maioria declarou que não foi ou não é membro de associações de pais e amigos dos surdos e isso pode ser prejudicial para 0 sentimento de pertencimento e competência em informação desses pais e, consequentemente, dos filhos surdos.

Igualmente, os eventos, encontros e festas para surdos influenciam o sentimento de pertencimento. Porém, na amostra analisada nem todos os pais participam de eventos da escola e da associação de pais com frequência, o que impossibilita o diálogo e o compartilhamento de informação com os demais pais.

No contexto da surdez, a igreja é um dos espaços importantes para apropriação e construção de identidade do surdo e da família. Outros eventos citados pelos participantes foram eventos sociais, políticos e palestras que contribuem para a promoção da competência em informação, com a participação social e política e exercício da cidadania. Ressaltamos que a falta de assiduidade dos pais em determinados momentos do ambiente social que o filho frequenta pode enfraquecer o grupo, dificultando o compartilhamento de informações e experiências.

Inferimos que os pais precisam participar mais ativamente da escola, da 
associação de pais e amigos dos surdos e de outras instâncias, assim como frequentarem eventos, participar de cursos de Libras promovidos pelas instituições. Ademais, observamos que as instituições que atendem os surdos ao desenvolverem atividades para aconselhar e auxiliar as famílias dos surdos poderiam promover discussões e disseminar informações sobre a surdez de modo que despertasse nos pais a necessidade de buscar outras informações por vontade própria. Ressaltamos que o fato de os pais sentirem-se pertencentes à comunidade de pais e à comunidade surda colabora para o aprender. Também ficou evidente a importância da fé e da religiosidade na vida dos pais. Foi possível notar que o conhecimento religioso torna os pais confiantes e seguros para lidar com a surdez, ao passo que a necessidade de pertencimento na família é favorecida.

Para a maioria dos pais o fato de se sentirem pertencidos à comunidade de pais sempre os ajudam a aprender a lidar com a surdez. Este resultado indicou que eles além de relacionar o pertencimento com a aprendizagem, concebem o próprio grupo de pais como fonte de informação sobre a surdez e acreditam que se sentir pertencidos à comunidade de pais ajuda a aprender a lidar com a surdez. Em muitos casos os próprios filhos surdos auxiliam e fortalecem os pais propiciando experiências de aprendizagem, crescimento pessoal com a surdez e, consequentemente, o desenvolvimento de habilidades para a competência em informação. Por fim, evidencia-se a relevância dos estudos da competência em informação considerar as variáveis emocionais e afetivas, na tentativa de compreender seus impactos na busca e apropriação da informação.

\section{REFERÊNCIAS}

AKAICHI, T. Compartilhamento da informação e do conhecimento na rede dos coordenadores dos Programas de Pós-Graduação em Ciência da Informação. 2014. 196 f. Dissertação (Mestrado em Ciência da Informação) Universidade Estadual de Londrina, Londrina, 2014.

\section{ALCARÁ, A. R. Orientações motivacionais de alunos do curso de}

Biblioteconomia de uma universidade pública do norte do Paraná. 2007. 127 f. Dissertação (Mestrado em Educação) - Universidade Estadual de Londrina, Londrina, 2007.

AMADEO, D. S.; VITORINO, E. V. Necessidades informacionais dos alunos do 
curso de letras Libras quanto à realização de pesquisas acadêmicas: um olhar inicial ao desenvolvimento da competência informacional dos alunos surdos. In: CONGRESSO BRASILEIRO DE BIBLIOTECONOMIA, DOCUMENTAÇÃO E CIÊNCIA DA INFORMAÇÃO, 25., 2013. Florianópolis. Anais [...] Florianópolis: CBDD, 2013. Disponível em:

https://anaiscbbd.emnuvens.com.br/anais/article/view/1417/1418. Acesso em: 17 abr. 2020.

AMERICAN LIBRARY ASSOCIATION (ALA). Presidential Committee on Information Literacy: Final Report. 1989. Disponível em: http://www.ala.org/acr//publications/whitepapers/presidential. Acesso em: 17 abr. 2020.

ASSOCIATION OF COLLEGE AND RESEARCH LIBRARIES (ACRL). Framework for Information Literacy for Higher Education. Chicago, 2016.

BAUMEISTER, R. F.; LEARY, M. R. The need to belong: desire for interpersonal attachments as a fundamental human motivation. Psycological Bulletin, Washington, v. 117, n. 4, p. 497-529, 1995.

BELLUZZO, R. C. B. O uso de mapas conceituais para o desenvolvimento da competência em informação: um exercício de criatividade. In: PASSOS, R.; SANTOS, G. C. (org.). Competência em informação na sociedade de aprendizagem. Bauru: Kayros, 2005.

BRASIL. Ministério da Educação. Saberes e práticas da inclusão: desenvolvendo competências para o atendimento às necessidades educacionais especiais de alunos surdos. 2. ed. Brasília: MEC, Secretaria de Educação Especial, 2006. 116 p. (Série: Saberes e práticas da inclusão). Disponível em: http://portal.mec.gov.br/seesp/arquivos/pdf/alunossurdos.pdf. Acesso em: 07 abr. 2020.

CHIELLA. V. E. Marcas surdas: escola, família, associação, comunidade e universidade constituindo cultura e diferença surda. 2007. 155 f. Dissertação (Mestrado em Educação) - Universidade do Vale do Rio dos Sinos, São Leopoldo, 2007. Disponível em:

http://repositorio.jesuita.org.br/bitstream/handle/UNISINOS/1937/marcas\%20su rdas.pdf?sequence=1\&isAllowed=y. Acesso em: 03 abr. 2020.

DECI, E. L.; RYAN, R. M. The "what" and "why" of goal pursuits: human needs and the selfdetermination of behavior. Psychological Inquiry, Londres, v. 11, n. 4, p. 227-268, 2000.

DIZEU, L. C. T. B.; CAPORALI, S. A. A Língua de Sinais constituindo o surdo como sujeito. Educação \& Sociedade, Campinas, v. 26, n. 91, p. 583-597, maio/ago. 2005. Disponível em:

http://www.scielo.br/pdf/es/v26n91/a14v2691.pdf. Acesso em: 07 abr. 2020. 
DULZAIDES IGLESIAS, M. E.; MOLINA GÓMEZ, A. La competencia informacional: concepción relevante a considerar en la Educación Superior. MediSur, Cienfuegos, v. 5, n. 1, p. 44-47, 2007. Disponível em: https://dialnet.unirioja.es/servlet/articulo?codigo=2951074. Acesso em: $07 \mathrm{abr}$. 2020.

FAZZIONI, D. P. D. M.; VIANNA, W. B.; VITORINO, E. V. O atual estágio conceitual da competência em informação em publicações de Língua Portuguesa. Ciência da Informação, Brasília, v. 47, n. 3, p. 193-206, set./dez. 2018. Disponível em: http://revista.ibict.br/ciinf/article/view/4228/3984. Acesso em: 17 abr. 2020.

GASTAL, C. A.; PILATI, R. Escala de necessidade de pertencimento: adaptação e evidências de validade. Psico-USF, Bragança Paulista, v. 21, n. 2, p. 285-292, maio/ago. 2016. Disponível em:

http://www.scielo.br/pdf/pusf/v21n2/2175-3563-pusf-21-02-00285.pdf. Acesso em: 17 abr. 2020.

GUARINELLO, A. C.; LACERDA, C. B. F. O grupo de familiares de surdos como espaço de reflexão e de possibilidades de mudança. In: MASSI, G.; SANTANA, A. P.; BERBERIAN, A. P.; GUARINELLO, A. C. (org.). Abordagens grupais em Fonoaudiologia: contextos e aplicações. São Paulo: Plexus, 2007. p. 105-120. v. 1. Disponível em: https://bit.ly/2DsQJuk. Acesso em: 17 abr. 2020.

GUIMARÃES, S. E. R.; BORUCHOVITCH, E. O estilo motivacional do professor e a motivação intrínseca dos estudantes: uma perspectiva da teoria da autodeterminação. Psicologia: Reflexão e Crítica, Porto Alegre, v. 17, n. 2, p. 143-150, 2004. Disponível em: http://www.scielo.br/pdf/prc/v17n2/22466.pdf. Acesso em: 07 abr. 2020.

LUCCA, D. M.; VITORINO, E. V. A dimensão política da competência em informação de idosos: em busca de princípios. In: ENCONTRO NACIONAL DE PESQUISA EM CIÊNCIA DA INFORMAÇÃO (ENANCIB), 19., 2018. Anais [...] Londrina: ENANCIB, 2018. p. 4116- 4124.

MANIFESTO de Florianópolis sobre a Competência em Informação e as Populações Vulneráveis e Minorias. In: SEMINÁRIO SOBRE COMPETÊNCIA EM INFORMAÇÃO: CENÁRIOS E TENDÊNCIAS, 2., 2013. Florianópolis. Anais [...] Florianópolis: FEBAB, IBICT, UNB e UNESP, 2013. Disponível em: encurtador.com.br/advG3. Acesso em: 07 abr. 2020.

PERASSINOTO, M. G. M. Estratégias de aprendizagem no ensino fundamental: relações com regulação emocional, motivação e rendimento escolar. 2011. 113 f. Dissertação (Mestrado em Educação) - Universidade Estadual de Campinas, Campinas, 2011. Disponível em: http://repositorio.unicamp.br/bitstream/REPOSIP/250788/1/Perassinoto_MariaG 
islaineMarques_M.pdf. Acesso em: 07 abr. 2020.

PEREIRA, A. P. A competência em informação dos pais de surdos. 2020. 158f. Dissertação (Mestrado em Ciência da Informação) - Universidade Estadual de Londrina, Londrina, 2020.

QUADROS, R. M. Educação de surdos: aquisição da linguagem. Porto Alegre: Artmed, 1997. 126 p.

REEVE, J.; DECI, E. L.; RYAN, R. M. Self-determination theory: a dialectical framework for understanding sociocultural influences on student motivation. In: McINERNEY, D. M.; VAN ETTEN, S. (ed.). Big theories revisited. Greenwich: Information Age Publishing, 2004. p. 31-60.

RYAN, R. M.; DECI, E. L. Self-dtermination theory: psychological needs in motivation, development, and wellness. New York: GuilfordPress, 2017.

SANTOS, C. A. Educação de usuários ou competência em informação (Colnfo)? Uma reflexão necessária. INFOhome, fev. 2016. Disponível em: https://www.ofaj.com.br/colunas_conteudo.php?cod=959. Acesso em: 17 abr. 2020.

SILVA, L. Língua Brasileira de Sinais - Libras. Curitiba: Fael Editora, 2010. $164 \mathrm{p}$.

SKLIAR, C. Os estudos surdos em Educação: problematizando a normalidade. In: SKLIAR, C. (org.). A surdez: um olhar sobre as diferenças. Porto Alegre: Mediação, 2012. 192 p. p. 7-32.

SOUZA, I. C. Alegria e prazer com a motivação para aprender. In: BERBEL, N. A. N.; ROSA, W. (org.) Reflexões de professores. Londrina: Grafcel, 2011. p. 89-93.

VITORINO, E. V.; PIANTOLA, D. Competência informacional - bases históricas e conceituais: construindo significados. Ciência da Informação, Brasília, v. 38, n. 3, p. 130-141, set./dez. 2009. Disponível em:

http://revista.ibict.br/ciinf/article/view/1236/1414. Acesso em: 07 abr. 2020.

\title{
INFORMATION LITERACY AND NEED TO BELONG FROM PARENTS OF THE DEAF
}

\begin{abstract}
Introduction: This research addresses the contribution of information literacy to the deaf parents' need to belong. The need for belonging involves the feeling of integration,
\end{abstract}


connection and acceptance of the individual by the group. In the case of deafness, this bond is established in the relationship between parents and the deaf community or with other parents, whether in the church, at school, in the parents' association, at events or meetings for the deaf. He emphasizes that the need for belonging can bring parents closer together and encourage them to seek, use and share information with each other, in order to strengthen these relationships and develop skills for information literacy. Objective: To analyze the information literacy of deaf parents and their contribution to the need for belonging. Methodology: Exploratory and descriptive study, of qualitative and quantitative nature from a field research. The locus was constituted by two institutions specialized in the area of deafness in the northern region of Paraná. The target population was composed of 34 parents of the deaf, whose children study at these institutions and the data were collected through a questionnaire. Results: Among the results, it was identified that most parents feel they belong to the deaf community, and this feeling tends to favor the bond, information sharing and participation in the lives of deaf children. Conclusions: It is concluded that the need for parents of deaf parents contributes to the information literacy by expanding skills and affective bonds.

Descriptors: Information literacy. Need to belong. Deafness.

\title{
ALFABETIZACIÓN INFORMACIONAL Y NECESIDAD DE PERTENECER DE LOS PADRES DE SORDOS
}

\begin{abstract}
RESUMEN
Introducción: Esta investigación aborda la contribución de la alfabetización informacional a la necesidad de pertenecer de los padres sordos. La necesidad de pertenencia implica el sentimiento de integración, conexión y aceptación del individuo por parte del grupo. En el caso de la sordera, este vínculo se establece en la relación entre los padres y la comunidad sorda o con otros padres, ya sea en la iglesia, en la escuela, en la asociación de padres, en eventos o reuniones para sordos. Él enfatiza que la necesidad de pertenencia puede acercar a los padres y alentarlos a buscar, usar y compartir información entre ellos, a fin de fortalecer estas relaciones y desarrollar habilidades para la alfabetización informacional. Objetivo: analizar la alfabetización informacional de los padres sordos y su contribución a la necesidad de pertenencia. Metodología: Estudio exploratorio y descriptivo, de naturaleza cualitativa y cuantitativa a partir de una investigación de campo. El locus estaba constituido por dos instituciones especializadas en el área de la sordera en la región norte de Paraná. La población objetivo estaba compuesta por 34 padres de sordos, cuyos hijos estudian en estas instituciones y los datos se recopilaron mediante un cuestionario. Resultados: Entre los resultados, se identificó que la mayoría de los padres sienten que pertenecen a la comunidad sorda, y este sentimiento tiende a favorecer el vínculo, el intercambio de información y la participación en la vida de los niños sordos. Conclusiones: Se concluye que la necesidad de padres de padres sordos contribuye a la alfabetización informacional al expandir habilidades y vínculos afectivos.
\end{abstract}

Descriptores: Alfabetización informacional. Necesita pertenecer. Sordera.

Recebido em: 18.04.2020

Aceito em:16.06.2020 